\title{
Nebulized Magnesium Sulphate in Bronchiolitis: A Randomized Controlled Trial
}

\author{
Roma Debbarma $^{1} \cdot$ Daisy Khera $^{1}$ (D) $\cdot$ Surjit Singh ${ }^{2} \cdot$ Nisha Toteja $^{3} \cdot$ Bharat Choudhary $^{4} \cdot$ Kuldeep Singh $^{1}$
}

Received: 16 October 2020 / Accepted: 4 February 2021 / Published online: 27 March 2021

(C) Dr. K C Chaudhuri Foundation 2021

\begin{abstract}
Objective To evaluate the efficacy and safety of nebulized magnesium sulphate as a bronchodilator in young children aged 1-24 mo with moderate to severe bronchiolitis in comparison to standard therapy.

Methods This was an open labeled randomized controlled trial comprising 60 children with moderate to severe bronchiolitis which was randomly assigned to 2 groups. Intervention group received nebulization with $3 \mathrm{~mL}$ of $3.2 \%$ magnesium sulphate $\left(\mathrm{MgSO}_{4}\right)$ (iso-osmolar) every 4 hourly for $24 \mathrm{~h}$ in addition to standard care and the control group received standard care alone. The primary outcome measure was to compare the improvement of bronchiolitis severity score (BSS) and length of hospitalization. The secondary outcome was to measure the need for noninvasive ventilation, need for admission to intensive care unit (ICU) in the initial visit, to evaluate the safety of magnesium sulphate and need for clinic revisit, hospital readmission and ICU readmission within $2 \mathrm{wk}$ after discharge in both the groups.

Results The mean age of children allocated in the control group was $7.4 \pm 5.1 \mathrm{mo}$ and $7.7 \pm 4.5 \mathrm{mo}$ in the intervention group. There was no significant difference with respect to improvement of BSS or reduced length of hospitalization in both the groups $(p>0.05)$. BSS monitored sequentially after enrollment at $1,2,4,8,12,16$, and $24 \mathrm{~h}$ did not show statistically significant differences between the groups. Mean length of hospital stay was $2.89 \pm 2.25 \mathrm{~d}$ in treatment group and $2.96 \pm 1.86 \mathrm{~d}$ in control group $(p=0.902)$. No adverse events were observed in both the groups.

Conclusion Nebulized magnesium sulphate is not superior to standard therapy in children with moderate to severe bronchiolitis.

Clinical Trial Registration Number CTRI/2018/06/014400.
\end{abstract}

Keywords Bronchiolitis · Bronchiolitis severity score (BSS) · Magnesium sulphate

\section{Introduction}

The American Academy of Pediatrics together with European Respiratory Society defines bronchiolitis as the "constellation of clinical signs and symptoms including a viral upper

Daisy Khera

daisykhera78@gmail.com

1 Department of Pediatrics, All India Institute of Medical Sciences, Jodhpur, Rajathan, India

2 Department of Pharmacology, All India Institute of Medical Sciences, Jodhpur, Rajathan, India

3 Department of Pediatrics, All India Institute of Medical Sciences, Gorakhpur, Uttar Pradesh, India

4 Department of Trauma \& Emergency (Pediatrics), All India Institute of Medical Sciences, Jodhpur, Rajathan, India respiratory prodrome followed by increased respiratory effort and wheeze in children less than 2 years" [1]. It accounts for up to $60 \%$ cases of lower respiratory infections and $32 \%$ of hospitalizations in the first year of life [2]. Respiratory syncytial virus (RSV) is the leading cause of acute bronchiolitis and manifests clinically as coryza, mild cough, low grade fever, tachypnoea, wheezing, and signs of respiratory distress [3]. Advocated treatment remains largely supportive which includes administration of oxygen, fluid therapy, and antipyretic medications [4]. Even though pathological concepts point towards therapeutic role of bronchodilators in mitigating effects of bronchial obstruction, this presumption has not been supported by the weight of scientific evidence so far.

Of particular interest is the ubiquitous role of magnesium in various physiological processes such as modulating the muscular excitability and influx of calcium across cellular membranes. This has led to a renewed interest in the research pertaining to its effect in various disease conditions [5]. 
Stipulated role of magnesium sulphate in effecting bronchodilation forms the rationale for its use in bronchial asthma. In fact, some reports indicate a superior effect even in those who are unresponsive to $\beta$-agonist treatments $[6,7]$. The clinical and pathological semblance between asthma and bronchiolitis has drawn several therapeutic analogies. There is paucity of literature on efficacy of magnesium sulphate in the treatment of bronchiolitis worldwide. No published literature is available from Indian subcontinent on this subject and the authors wish to shed light on this subject by the present research study.

\section{Material and Methods}

This was an open label randomized controlled trial conducted at All India Institute of Medical Sciences (AIIMS), Jodhpur, Rajasthan between November 2018 and December 2019. Eligibility for enrollment included all pediatric patients aged 1 mo to 24 mo, hospitalized with a clinical diagnosis of acute bronchiolitis with bronchiolitis severity score (BSS) $\geq 4$ at admission (moderate to severe bronchiolitis). Definition of bronchiolitis included first episode of wheezing along with symptoms suggestive of upper respiratory tract infection such as rhinorrhea, cough, and low-grade fever. The Wang BSS [8] ranges from 0 to 12 and has four variables, each receiving a score from 0 to 3 ; increasing scores denote worse status. Those with previous history of wheezing, imminent need for mechanical ventilation at admission, hemodynamically significant heart disease, chromosomal anomalies, immunodeficiency, cystic fibrosis, bronchopulmonary dysplasia, and epileptic encephalopathy were excluded.
Ethical committee approval was obtained from the institutional ethics committee, AIIMS Jodhpur. Written informed consent was obtained from one of the parents of each child before start of the therapy. Participants were randomly divided into two groups, with a 1:1 allocation ratio. Simple complete randomization list using random allocation rule, was generated using random allocation software. Concealment of randomization was achieved using sequentially numbered opaque sealed envelopes. All patients received standard care including hydration and humidified oxygen administration. Allocated intervention was implemented as per the directives on the envelopes. Intervention group received nebulization with $3 \mathrm{~mL}$ of $3.2 \%$ magnesium sulphate $\left(\mathrm{MgSO}_{4}\right)$ (isoosmolar) every 4 hourly for $24 \mathrm{~h}$ in addition to standard care whereas control group received standard care alone. Oxygen saturation was noted before starting the treatment and oxygen was supplemented if the saturation was less than $94 \%$. All children were monitored continuously throughout the study duration. In the event of persistent hypoxia unresponsive to oxygen therapy, child was considered a candidate for mechanical ventilation.

BSS, respiratory rate (RR), peripheral capillary oxygen saturation $(\mathrm{SpO} 2)$, heart rate $(\mathrm{HR})$ was recorded before initiation of treatment and subsequently at $1,2,4,8,12,16$, and $24 \mathrm{~h}$ during the hospital stay. Vital parameters were recorded and the BSSs were assigned by the study physician. The study consisted of 60 cases, 28 in treatment group and 32 in control group. The primary outcome was a comparison of improvement of BSSs in between the two treatment groups from admission till $24 \mathrm{~h}$ after admission and length of hospitalization. The secondary outcome was to measure the need for noninvasive ventilation, need for admission to intensive care unit (ICU) in the initial visit, to evaluate the safety of magnesium
Fig. 1 CONSORT flow diagram for the study. ITT Intention to treat; LAMA Left against medical advice; $\mathrm{MgSO}_{4}$ Magnesium sulphate

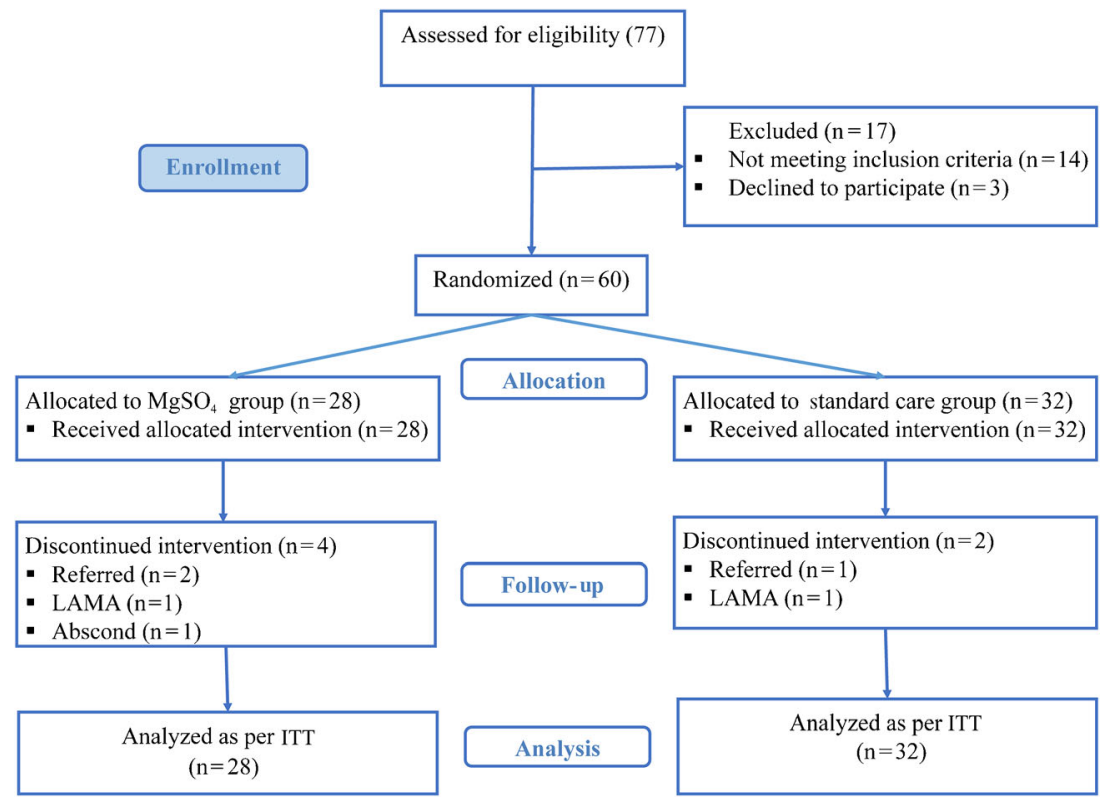


Table 1 Baseline characteristics of the study groups

\begin{tabular}{lllc}
\hline $\begin{array}{l}\text { Baseline characteristics } \\
\text { (at admission) }\end{array}$ & $\begin{array}{l}\text { Control } \\
(\mathrm{n}=32) \\
\text { Mean } \pm \mathrm{SD}\end{array}$ & $\begin{array}{l}\mathrm{MgSO}_{4} \\
(\mathrm{n}=28) \\
\text { Mean } \pm \mathrm{SD}\end{array}$ & $\begin{array}{c}p \text { value }^{\dagger} \\
\text { (2-sided) }\end{array}$ \\
\hline Age (mo) & $7.40 \pm 5.10$ & $7.73 \pm 4.51$ & 0.796 \\
Duration of illness (d) & $3.96 \pm 2.17$ & $4.64 \pm 2.48$ & 0.267 \\
Coryza n (\%) & $31(96.9)$ & $27(96.4)$ & $>0.9$ \\
Fever n (\%) & $25(78.1)$ & $25(89.3)$ & 0.312 \\
Cough n (\%) & $32(100)$ & $28(100)$ & $>0.9$ \\
Noisy breathing n (\%) & $30(93.8)$ & $28(100)$ & 0.494 \\
Chest indrawing (\%) & $28(87.5)$ & $25(89.3)$ & $>0.9$ \\
Feeding difficulty n (\%) & $25(78.1)$ & $17(60.7)$ & 0.167 \\
Heart rate (beats/min) & $152.2 \pm 18.8$ & $185.1 \pm 188.0$ & 0.329 \\
Respiratory rate (breaths/min) & $57.8 \pm 7.76$ & $59.8 \pm 7.61$ & 0.418 \\
Oxygen saturation (\%) & $96.2 \pm 2.76$ & $95.5 \pm 3.88$ & 0.405 \\
Temperature (degree Fahrenheit) & $99.0 \pm 1.28$ & $98.8 \pm 1.13$ & 0.493 \\
Oxygen requirement (L/min) & $1.23 \pm 1.18$ & $1.50 \pm 1.37$ & 0.425 \\
BSS & $6.28 \pm 1.57$ & $6.71 \pm 1.69$ & 0.309 \\
\hline
\end{tabular}

BSS Bronchiolitis severity score sulphate and need for clinic revisit, hospital readmission and ICU readmission within 2 wk after discharge in both the groups. Patients were considered ready for discharge if they did not need supplemental oxygen to maintain $\mathrm{SpO} 2>94 \%$, were feeding adequately, had minimal or absent wheezing/ crackles, and $\mathrm{BSS}<4$.

Sample size calculation was based on the study results of Modaresi et al. [9]. The sample size for each group was calculated based on a significance level of $\alpha=0.05$ and a power (1- $\beta$ ) of $80 \%$ to detect a clinically meaningful mean difference in Respiratory Distress Assessment Instrument (RDAI) score of 2 (based on clinician's opinion) and standard deviation of 2.2 and 2.6 in RDAI score between the groups, sample size was estimated to be 23 per group. Taking into consideration $20 \%$ dropout rate, sample size of 28 in each group was required.

Statistical analysis: The primary analysis was performed as per Intention to Treat (ITT) analysis. Similar technique was used to analyze all secondary outcome measures. Mean difference between the two groups was analyzed using student's $t$-test and categorical data analyzed by Fischer exact test. Data were analyzed using the SPSS, version 23 (IBM SPSS Statistics for Windows, Version 23.0. Armonk, NY: IBM Corp.). Significant values were reported with their corresponding $95 \%$ confidence intervals and $p$ value $<0.05$ was considered to signify a threshold for statistical significance.

\section{Results}

During the study period, 77 patients with a clinical diagnosis of bronchiolitis were assessed for recruitment. Of these, 17 were excluded according to the pre-set criteria laid down in the study protocol. Figure 1 represents CONSORT flow diagram depicting selection, randomization, and follow-up of participants in the study. Thus, a total of 60 children with moderate-severe bronchiolitis were recruited in the study with the mean age of $7.4 \pm 5.1 \mathrm{mo}$ in control group and $7.7 \pm 4.5$ mo in the $\mathrm{MgSO}_{4}$ group. Total 28 children were allocated to receive nebulized magnesium sulphate as an intervention. In this group, there was attrition of 4 patients due to nonavailability of beds. In the control group, there were 32 enrolled children, of which, two cases were lost to follow-up. Thus, all randomized children in both the groups were analyzed, as an intention to treat analysis. The baseline characteristics of both the groups were comparable and are depicted in Table 1.

For primary outcome (Table 2), there was no statistically significant difference in BSS between the control group and

Table 2 Mean values of BSS in two treatment groups at different time intervals

\begin{tabular}{llll}
\hline Parameters & $\begin{array}{l}\text { Control } \\
(\mathrm{n}=32) \\
\text { Mean } \pm \mathrm{SD}\end{array}$ & $\begin{array}{l}\mathrm{MgSO}_{4} \\
(\mathrm{n}=28)\end{array}$ & $\begin{array}{l}p \text { value }^{\dagger} \\
\text { (2-sided) }\end{array}$ \\
\hline BSS at $1 \mathrm{~h}$ & $5.93 \pm 1.79$ & $6.17 \pm 1.72$ & 0.599 \\
BSS at $2 \mathrm{~h}$ & $4.96 \pm 1.75$ & $5.35 \pm 1.63$ & 0.381 \\
BSS at $4 \mathrm{~h}$ & $4.31 \pm 1.85$ & $4.25 \pm 1.35$ & 0.883 \\
BSS at $8 \mathrm{~h}$ & $3.84 \pm 1.76$ & $3.42 \pm 1.37$ & 0.318 \\
BSS at $12 \mathrm{~h}$ & $3.06 \pm 1.45$ & $3.37 \pm 1.80$ & 0.478 \\
BSS at $16 \mathrm{~h}$ & $2.61 \pm 1.56$ & $3.22 \pm 2.15$ & 0.219 \\
BSS at $24 \mathrm{~h}$ & $2.26 \pm 1.50$ & $2.12 \pm 1.71$ & 0.750 \\
\hline
\end{tabular}

BSS Bronchiolitis severity score; $\mathrm{MgSO}_{4}$ Magnesium sulphate 
Table 3 Mean length of hospital stay and duration of oxygen requirement in two groups

\begin{tabular}{llll}
\hline Time & $\begin{array}{l}\text { Control } \\
(\mathrm{n}=32) \\
\text { Mean } \pm \mathrm{SD}\end{array}$ & $\begin{array}{l}\mathrm{MgSO}_{4} \\
(\mathrm{n}=28) \\
\text { Mean } \pm \mathrm{SD}\end{array}$ & $\begin{array}{l}p \text { value }^{\dagger} \\
\text { (2-sided) }^{-}\end{array}$ \\
\hline Length of hospital stay (d) & $2.96 \pm 1.86$ & $2.89 \pm 2.25$ & 0.902 \\
Duration of oxygen requirement (h) & $21.7 \pm 28.76$ & $25.7 \pm 21.79$ & 0.886 \\
\hline
\end{tabular}

$\mathrm{MgSO}_{4}$ Magnesium sulphate

the study group $(p>0.05)$. The mean length of hospitalization was $2.96 \mathrm{~d}$ in control group whereas it was $2.89 \mathrm{~d}$ in intervention group ( $p$ value $=0.902$ ). Likewise, no significant difference in duration of oxygen requirement was noted between the two groups (Table 3).

For other secondary outcomes, among 60 children, the need for ICU admission was seen in 2 cases in the control group and 5 cases in the intervention group with statistically insignificant difference between the two groups ( $p$ value $>0.05$ ), whereas 3 cases in the control group and 6 cases in the intervention group required noninvasive ventilation in the form of indigenous continuous positive airway pressure (CPAP) and the results were statistically insignificant with $p$ value of $>0.05(0.281)$. No acute cardiorespiratory instability as an adverse effect was noted during the study period. There was one clinic revisit and readmission in the $\mathrm{MgSO}_{4}$ group within 2 wk of discharge not requiring ICU admission, whereas no clinic revisit, hospital readmission or ICU requirement in the control group.

Complete blood count (CBC) was done in 22 cases, among which only one patient had neutrophilia, which was associated with high C-reactive protein (CRP) and had BSS of 7 at admission, with length of hospital stay for $1 \mathrm{~d}$ and was not started on antibiotics as he improved in a day. Among 60 children, CRP was done in 10 cases in the control group and 12 cases in magnesium sulphate group, in which there was clinical suspicion of pneumonia, out of which nine cases were positive in each group. Similarly, chest radiography was done in 12 cases in control group, which showed bilateral infiltrates with or without hyperinflation in 9 cases, while in those children treated with $\mathrm{MgSO}_{4}$ nebulization, chest radiography was done in 7 cases with findings of bilateral infiltrates with or without hyperinflation seen in 6 cases. Outcome of CRP and chest radiography findings in both the groups are shown in Table 4.

\section{Discussion}

Acute bronchiolitis contributes to significant economic burden in resource-poor countries. Despite the widespread prevalence, no medication has emerged as a potential game changer in the treatment of acute bronchiolitis for many years. Metaanalyses of data on the commonly used therapies for acute bronchiolitis, namely nebulized bronchodilators, epinephrine, glucocorticoids, and chest physiotherapy have failed to prove any effect on relevant clinical outcomes, in comparison with placebo $[10,11]$.

In recent studies, $\mathrm{MgSO}_{4}$ has emerged as a potential adjunctive treatment in the management of acute bronchial asthma particularly in those resistant to $\beta 2$ agonists [12]. However, its role in bronchiolitis has not been studied as
Table 4 Comparison of need for ICU admission, NIV requirement, and outcome of CRP and chest radiograph findings in both the groups

\begin{tabular}{lllll}
\hline & $\begin{array}{l}\text { Control } \\
\mathrm{n}(\%)\end{array}$ & $\begin{array}{l}\mathrm{MgSO}_{4} \\
\mathrm{n}(\%)\end{array}$ & $\begin{array}{l}\text { Fisher exact } \\
p \text { value }^{\dagger} \\
(2 \text {-sided })\end{array}$ & $\begin{array}{l}\text { M-H OR (95\% CI) } \\
p \text { value }^{\dagger} \\
(2 \text {-sided })\end{array}$ \\
\hline ICU admission & $2(6.3)$ & $5(17.9)$ & 0.235 & $3.26(0.58-18.34)$ \\
NIV requirement & $3(9.4)$ & $6(21.4)$ & 0.281 & 0.18 \\
CRP & & & & $2.63(0.59-11.7)$ \\
Positive & $9(90)$ & $9(75)$ & 0.594 & 0.20 \\
$\begin{array}{l}\text { Negative } \\
\text { Chest radiograph findings }\end{array}$ & $1(10)$ & $3(25)$ & & $0.333(0.029-3.842)$ \\
$\begin{array}{l}\text { Infiltrates } \pm \text { hyperinflation } \\
\text { Normal }\end{array}$ & $9(75)$ & $6(85.7)$ & $>0.99$ & $2.0(0.166-24.069)$ \\
& $3(25)$ & $1(14.3)$ & & 0.585
\end{tabular}

$C I$ Confidence interval; $C R P$ C-reactive protein; ICU Intensive care unit; $M-H$ OR Mantel-Haenszel odds ratio; NIV Non-invasive ventilation 
extensively. In fact, there have been only three studies, so far, evaluating the efficacy of nebulized $\mathrm{MgSO}_{4}$ in the treatment of bronchiolitis. Alansari et al. evaluated the role of intravenous magnesium sulphate in a cohort of 162 children and concluded that it did not provide any benefit [7].

Amongst the studies on nebulized $\mathrm{MgSO}_{4}$, noteworthy is the research by Modaresi et al. [9, 13]. They conducted two studies with 60 and 120 children in 2012 and 2015, respectively. In both the studies, modest improvement in respiratory distress assessment index (RDAI) was found in the nebulized magnesium sulphate group. In the latter study comparison was made between nebulized $\mathrm{MgSO}_{4}$ and nebulized epinephrine. However, they also failed to demonstrate any significant impact on duration of hospitalization or any other tangible clinical benefit in terms of reduction of need for oxygen/ventilator support.

Another study comparing nebulized $\mathrm{MgSO}_{4}$ with salbutamol was conducted by Kose et al. [14] in a cohort of 56 infants with bronchiolitis. They concluded that treatment scores were better in the group with both $\mathrm{MgSO}_{4}$ and salbutamol than either alone. However, in the present study, primary outcome of BSSs in both the groups were statistically not significant $(p=0.883)$.

The reason for the lack of efficacy of $\mathrm{MgSO}_{4}$ found in the present study may be because of the relatively younger profile of cases. Younger children with bronchiolitis may not respond to $\mathrm{MgSO}_{4}$ well as older children with asthma. Also, the key pathophysiological distinction in asthma is that of reversible bronchospasm which is characteristically absent in bronchiolitis.

In this randomized controlled trial, the authors also documented that majority of children with bronchiolitis belonged to the age group between 6 mo and $1 \mathrm{y}(48 \%)$, being more common in male children $(75 \%)$ than female children $(25 \%)$. These findings were similar to the previous studies conducted by Modaresi et al. [9] and Kose et al. [14]. A study conducted by Nagayama et al. [15] and Boezen et al. [16] have stated that the possible reason for increased susceptibility could be due to the immunosuppressive effect of the male hormone.

Cough was the most common symptom in both the groups in the present study, which was consistent with the study findings by Wright et al. [17].

The present study also showed that the most common chest radiography finding in bronchiolitis was bilateral infiltrates with or without hyperinflation in both the groups. Chest radiograph abnormality was associated with fever in $88.9 \%$ cases and oxygen saturation of less than $94 \%$ in $22.2 \%$ cases at admission in the control group and in $100 \%$ cases and $28.6 \%$ cases in $\mathrm{MgSO}_{4}$ group, respectively. In the study conducted by Garcia et al. [18], majority of infants with bronchiolitis had a normal chest radiograph but temperature $\geq 38$ degree and oxygen saturation of $<94 \%$ were significantly associated with infiltrates/atelectasis stating that the absence of fever and hypoxia are good predictors of normal chest radiograph. The absence of fever and hypoxia could also be considered as predictors of favorable clinical outcome.

The study conducted by Kaur et al. [19], Costa et al. [20], and Fares et al. [21] concluded that CRP was increased in cases of bacterial co-infection and is helpful in deciding the initiation of antibiotics and also predicting the disease severity. Similarly, in the present study, 1 child in control group and 2 in $\mathrm{MgSO}_{4}$ group received intravenous antibiotics for suspected bacterial infection as they had high C-reactive protein (CRP) associated with bilateral infiltrates on chest radiograph, high grade fever and severe respiratory distress.

The limitation of the present study is that blinding was not done and study observation of BS scoring was only for $24 \mathrm{~h}$.

\section{Conclusion}

As with other negative studies, this study concludes that magnesium sulphate in an aerosolized formulation was not found to be superior to standard therapy for symptomatic alleviation in infants with moderate-severe bronchiolitis both in terms of severity score or length of hospitalization. Further large-scale trials are required to prove/disprove its clinical benefits.

Authors' Contribution All authors made substantial contributions to the drafting of the work and revising it critically for important intellectual content and finally approved the version to be published and agreed to be accountable for all aspects of the work in ensuring that questions related to the accuracy or integrity of any part of the work are appropriately investigated and resolved. KS will act as guarantor for this paper.

\section{Declarations}

Conflict of Interest None.

\section{References}

1. Ravaglia C, Poletti V. Recent advances in the management of acute bronchiolitis. F1000Prime Rep. 2014;6:103.

2. McConnochie KM, Roghmann KJ, Liptak GS. Hospitalization for lower respiratory tract illness in infants: variation in rates among counties in New York state and areas within Monroe County. J Pediatr. 1995;126(2):220-9.

3. Gupta S, Shamsundar R, Shet A, Chawan R, Srinivasa H. Prevalence of respiratory syncytial virus infection among hospitalized children presenting with acute lower respiratory tract infections. Indian J Pediatr. 2011;78:1495-7.

4. Castro-Rodriguez JA, Rodriguez-Martinez CE, Sossa-Briceno MP. Principal findings of systematic reviews for the management of acute bronchiolitis in children. Paediatr Respir Rev. 2015;16(4): 267-75.

5. Singhi S, Grover S, Bansal A, Chopra K. Randomised comparison of intravenous magnesium sulphate, terbutaline and aminophylline for children with acute severe asthma. Acta Paediatr. 2014;103(12): 1301-6. 
6. Scarfone RJ, Loiselle JM, Joffe MD, et al. A randomized trial of magnesium in the emergency department treatment of children with asthma. Ann Emerg Med. 2000;36(6):572-8.

7. Alansari K, Sayyed R, Davidson BL, Jawala SA, Ghadier M. IV Magnesium sulfate for bronchiolitis: a randomized trial. Chest. 2017;152(1):113-9.

8. Wang EE, Milner RA, Navas L, Maj H. Observer agreement for respiratory signs and oximetry in infants hospitalized with lower respiratory infections. Am Rev Respir Dis. 1992;145(1):106-9.

9. Modaresi MR, Faghihinia J, Kelishadi R, et al. Nebulized magnesium sulfate in acute bronchiolitis: a randomized controlled trial. Indian J Pediatr. 2015;82(9):794-8.

10. Gadomski AM, Scribani MB. Bronchodilators for bronchiolitis. Cochrane Database Syst Rev. 2014;2014(6):CD001266.

11. Ralston SL, Lieberthal AS, Meissner HC, et al. Clinical practice guideline: the diagnosis, management, and prevention of bronchiolitis. Pediatrics. 2014;134(5):e1474-502.

12. Ciarallo L, Sauer AH, Shannon MW. Intravenous magnesium therapy for moderate to severe pediatric asthma: results of a randomized, placebo-controlled trial. J Pediatr. 1996;129(6):809-14.

13. Modaresi M, Faghihinia J, Mirlohi H, Pjang F. The effectiveness of magnesium sulfate nebulizer in treatment of acute bronchiolitis. Paediatr Respir Rev. 2012;13:S58.

14. Kose M, Ozturk MA, Poyrazoğlu H, et al. The efficacy of nebulized salbutamol, magnesium sulfate, and salbutamol/magnesium sulfate combination in moderate bronchiolitis. Eur J Pediatr. 2014;173(9): 1157-60.

15. Nagayama Y, Tsubaki T, Nakayama S, et al. Gender analysis in acute bronchiolitis due to respiratory syncytial virus. Pediatr Allergy Immunol. 2006;17(1):29-36.

16. Boezen HM, Jansen DF, Postma DS. Sex and gender differences in lung development and their clinical significance. Clin Chest Med. 2004;25(2):237-45.

17. Wright A, Taussig LM, Ray CG, Harrison HR, Holberg CJ. The Tucson children's respiratory study. II. Lower respiratory tract illness in the first year of life. Am J Epidemiol. 1989;129:1232-46.

18. Garcia Garcia ML, Sergio Jose QuevedoTeruel S, Calvo Rey C, Martinez Perez M. Chest radiograph in bronchiolitis: is it always necessary? An Pediatr (Barc). 2004;61(3):219-25.

19. Kaur J, Narang G, Arora S. Role of CRP in lower respiratory tract infections. J Nepal Paediatr Soc. 2013;33(2):117-20.

20. Costa S, Rocha R, Tavares M, Bonito Vítor A, GuedesVaz L. C reactive protein and disease severity in bronchiolitis. Rev Port Pneumol. 2009;15(1):55-65.

21. Fares M, Mourad S, Rajab M, Rifai N. The use of C-reactive protein in predicting bacterial co-infection in children with bronchiolitis. $\mathrm{N}$ Am J Med Sci. 2011;3(3):152-6.

Publisher's Note Springer Nature remains neutral with regard to jurisdictional claims in published maps and institutional affiliations. 